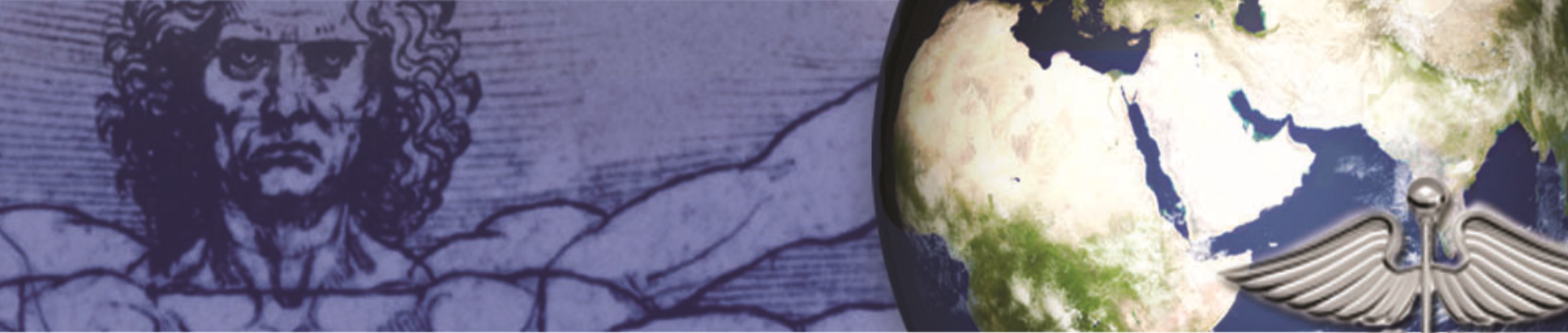

\title{
Health, Culture and Society
}

\section{Health Care and Women's Empowerment:}

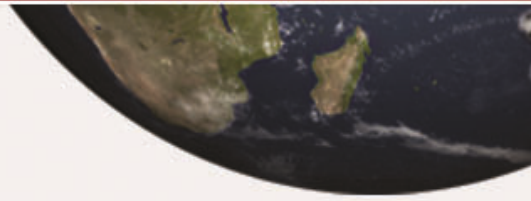

The role of Self Help Groups

S. Chakravarty \& A.N. Jha

Volume 2, No. 1 (2012) | ISSN 2161-6590 (online) DOI 10.5195/hcs.2012.56 | http://hcs.pitt.edu

\section{(cc) EY-NC-ND}

This work is licensed under a Creative Commons Attribution-Noncommercial-No Derivative Works 3.0 United States License.

\section{UILIS D-Sente}

This journal is published by the University Library System of the University of Pittsburgh as part of its D-Scribe Digital Publishing Program, and is cosponsored by the University of Pittsburgh Press. 


\begin{abstract}
Over the last couple of decades the concept of Self Help Groups (SHGs) and its potential as an effective tool to alleviate poverty and empower women has garnered considerable interest worldwide. Considering the importance given by policy makers across various nations to the group approach while conceptualizing, formulating and implementing any scheme or programme for the welfare of marginalized and underprivileged sections of the society (especially women), we identified the need to critically examine and explore the role of SHGs in the empowerment of women with a special emphasis on health status.

To date, the functioning of SHGs has essentially been viewed only from an economic perspective. The existing approach puts encourages the economic development of women, with SHGs a mechanism to achieving this. However, how these economic benefits are being translated into the change in women's status, particularly their health status, remains unexplored and ultimately unaddressed.

This working research paper attempts to review the scope and limitations of SHGs in improving women's health and empowerment based upon empirical work undertaken in the Jharkhand state of India. Our paper also explores the extent to which SHGs can be involved in attaining better health status for women, and thereby point the way for further research.
\end{abstract}

Keywords: Women's empowerment; health care; SHGs; socio-economic status; poverty alleviation; India.

Health, Culture and Society 


\title{
Health Care and Women's Empowerment:
}

\section{The role of Self Help Groups}

\author{
S. Chakravarty ${ }^{1}$ \& A.N. Jha ${ }^{2}$
}

\section{Introduction: The concept of Self Help Groups}

SHGs are voluntary associations of 10-20 persons (generally women) who come together to solve their problems based upon mutual help and collective basis. The main reason behind the formation of SHGs is that poor people find it extremely hard to solve their problems individually but once they form a group it becomes considerably easier to tackle problems. These groups are known by different names in different places. Some of the terms used in India for these groups are - Sangha, Samooh, Mandal, Dangham, Samiti, depending upon the region. Most authors trace the history of "modern" self help groups to the 1935 founding of Alcoholics Anonymous(AA) ${ }^{1}$ in the US, this, a group that became active in a field in which existing social and health services did not provide adequate support.

SHGs may be viewed as voluntary gatherings of persons who share needs or problems that are not being addressed by existing organizations, institutions or other types of groups. The broad goals of SHGs include bringing about personal and social economic change for their members and society. All of these groups pay strong emphasis upon face to face interaction among members and also stress upon a set of values or ideology that could enhance a member's personal sense of identity. The SHG movement has gained momentum in India since the 1990s and various such groups are functioning in villages striving to bring about an upliftment in the socio-economic status of those who join, thereby empowering them.

The working pattern of SHGs is a standardized one. SHGs have a system of voluntary member funding the proceeds of which can be distributed to needy members for productive activities, as well as being channeled into medical expenses and aid relief. SHGs also take out bank loans or seek support from voluntary agencies or self promoting institutions to meet the needs of members.

\section{The purpose of SHGs}

The primary objective of self help groups is to engage the members in income generating activities and thereby make them self reliant. However, from a broader viewpoint, SHGs are held to be a potent tool and social mechanism for women's empowerment and poverty alleviation strategies.

Such a group based approach enables poor women to accumulate capital by way of small savings and facilitates their access to formal credit facilities (Shylendra, 1998). The concept of joint liability embedded in the SHG structure thus enables members to overcome the problems of collateral security, a major barrier to obtaining credit from formal institutions. This also leads to peer monitoring that improves the rate of loan recoveries (Stiglitz,

\footnotetext{
${ }^{1}$ Birla Institute of Technology, Lalpur Campus, Ranchi

${ }^{2}$ Birla Institute of Technology, Lalpur Campus, Ranchi
} 
1993). Further, some of the basic characteristics of SHGs, such as small size and homogeneity of composition, bring about cohesiveness and effective participation of members in the functioning of the group (Fernandez, 1994).

Of late, apart from generating employment opportunities for the SHG members, SHGs are also actively engaged in providing health care related services. This development drive is important because health is a crucial variable in over-all women empowerment. Other objectives of SHGs such as the reduction of infant mortality, the control of HIV/AIDS, the reduction of pregnancy deaths, the implementation of family planning schemes to enhance the socio-economic status of women, all converge towards a common motive, namely, ensuring the sound health of women, thereby actualizing female empowerment.

\title{
Rationale for the Self Help approach in Health System Strategy
}

The necessity to empower communities into taking charge and initiating lead of their health related issues has featured high on the agenda of policy makers and social activists world-wide. This urgency has frequently been argued with self help being recognized as a necessary component of primary health care strategy, one prioritizing the ethos of, people's health in people's hands (Robinson D, 1980). One of the core principles of self help is that only those experiencing the problem can understand it, this, allotting immense value to biographical experience and first-person narratives in illness and health (Robinson D, 1981). The comprehensive and still up-to-date definition of self help groups given by Katz \& Bender 1976 thus bodes well:

\begin{abstract}
Self help groups are voluntary, small group structures for mutual aid and the accomplishment of a special purpose. They are usually formed by peers who have come together for mutual assistance in satisfying a common need, overcoming a common handicap or life-disrupting problem, and bringing about desired social and/or personal change. The initiators and members of such groups perceive that their needs are not, or cannot be, met by or through existing social institutions. Self help groups emphasize face-to-face social interactions and the assumption of personal responsibility by members. They often provide material assistance, as well as emotional support: they are frequently "cause" oriented, and promulgate an ideology or values through which members may attain an enhanced sense of personal identity.
\end{abstract}

It may be noted, furthermore, that SHGs generally form as a collective, communal response to a condition of powerlessness and/or subversion experienced by poor people. Members act independently without being urged or coerced by any outside authority; they engaging in actions, personally participating, deriving both a collective valuation and benefit. Self help groups create, and indeed act, within a purposefully organized frame - this being the point of distinction with medical self-care, which is practiced by individuals alone or within a family (Katz, 1981).

\section{Microfinance and SHGs}

Although SHGs existed (and still do exist although rarely) without being linked with microfinance strategies, to properly appreciate the concept of SHGs a brief understanding of microfinance is required. Robinson (2001) defines microfinance as a small financial service in the form of credit and savings, provided to people who farm, fish or herd. He further adds that it refers to all types of financial services provided to low-income households and enterprises. In simpler words, microfinance can be defined as the supply of basic financial services (such as micro loans; savings; financial remittance; pensions and insurance schemes) to the less favored sectors of society.

In the context of Microfinance SHGs can be viewed as a model, or vehicle, for delivering products and services to the Poor. This said, because of its flexibility and scope of adaptability, SHG based microfinance has emerged as a tool to alleviate poverty and empower women. Banks may directly provide financial assistance to SHGs building upon the existing savings of the group or the Non-Government Organizations (NGOs) which act as financial intermediaries between banks and SHGs. Institutions, which independently or in collaboration with banks provide financial services to SHGs, are thus referred to as Micro Finance Institutions (MFIs).

Health Care and Women's Empowerment

Volume 2, No. 1 (2012) | ISSN 2161-6590 (online) | DOI 10.5195/hcs.2012.56 | http://hcs.pitt.edu 
The common characteristics of the SHG based microfinance model are:

- The attendance of regular weekly/fortnightly meetings by group members

- Training in 'loan utilization' or participation in discussions of developmentally relevant issues such as social discrimination; gender awareness; health; sanitation and education provided to the members by the concerned MFI/NGO

- Contribution of fixed termed amounts such as 'savings', to a fund managed either by the group or by the MFI with direct access by the members.

- Repayments of fixed amounts as installments on any loan that members obtain from the MFI or the group

SHG members receive in return for fulfilling these obligations:

- A fixed loan for engaging in productive activities with the size of the loan usually determined by the longevity of the member's history with the MFI rather than her financial status.

- Emergency loans for 'consumption' in the case of some MFIs. Such loans are of relatively small amount and subject to the approval of the SHG group, which in this case acts as a steering committee.

- Insurance provided by a risk fund or insurance fund backed by a few MFIs or an insurance company in collaboration with the MFI.

- Other development services, in the case of multi-service NGOs/MFIs.

\section{Empowerment through SHGs}

It is widely believed that SHGs have emerged as a powerful tool to alleviate poverty and empower rural women to actualize both their potential and identity. It is effective in bringing about social and economic changes in rural areas by facilitating the managerial abilities of women and developing community value. SHGs and microfinance are found to be crucial instruments in promoting empowerment of these women leading to social and economic development and enhancement of the community profile. The widespread perception is that the savings and credit facilities provided by SHGs can indeed lead to economic self reliance. However, there are certain debates emerging which focus on the pragmatics of long-term empowerment and as to what exactly constitutes successful empowerment and social articulation over this period.

There are indeed different opinions and definitions of empowerment depending upon the context. Empowerment in its broadest sense is widely acknowledged to be the, "expansion of freedom, of choice and action" (Narayan, 2002). Jo Rowland (1998) has rightly pointed out that the, "current use of the term [empowerment] remains ill-defined however, in the developmental context its users tend to assume that the appropriate meaning will be understood without being explained." Rowland also mentions that, "much use of the term has laid emphasis on economic and political empowerment and a conception of empowerment well rooted in the 'dominant culture' of Western Capitalism." The United Nations (2001) likewise defines empowerment as, "the process by which women take control and ownership of their lives through expansion of their choices." Although there is no standard definition or clear consensus of the term, empowerment, in the context of women's development, is a way of 
defining, challenging and overcoming barriers in a woman's life through which she increases her ability to shape her world and environment. It is an active, multidimensional process, which enables women to realize their full identity and power in all spheres of life. In such a context of empowerment it is assumed that when women come together via SHGs they find strength and move towards further knowledge and greater social actualization.

\section{Jharkhand State: the Socio-Economic Scenario}

Jharkhand, the $28^{\text {th }}$ State of the Indian Republic, came into being on $15^{\text {th }}$ November 2000 after the bifurcation of the Bihar State. Approximately $23 \%$ of the State is covered by forests. Being the oldest geological formation in India, there are vast deposits of minerals such as iron-ore; bauxite; copper; uranium. The land is crisscrossed by hills and rivers. Yet despite its mineral richness and natural resources, Jharkhand remains one of the most backward States in India and ever since its inception it has been plagued by adverse conditions: low average income, a high incidence of poverty and very little social development. The initial level of rural poverty, pegged at 49\% by the National Sample Survey (NSS.55 ${ }^{\text {th }}$ round of 1999/2000), was the highest among all Indian States, followed by Orissa (48\%) and Bihar (44\%).

As our research demonstrates, development indicators in Jharkhand are also markedly unfavorable to both the all-India average and the major Indian States. The health, demographic and socio-economic profile for most parameters does not compare favorably with the all India figures as illustrated below:

\begin{tabular}{|c|l|c|c|}
\hline S. No. & \multicolumn{1}{|c|}{ Item } & Jharkhand & India \\
\hline 1 & Total population (Census 2001) (in millions) & 26.9 & 1028.61 \\
\hline 2 & Decadal Growth (Census 2001) (\%) & NA* & 21.54 \\
\hline 3 & Crude Birth Rate (SRS 2008) & 25.8 & 22.8 \\
\hline 4 & Crude Death Rate (SRS 2008) & 7.1 & 7.4 \\
\hline 5 & Total Fertility Rate (SRS 2008) & 3.2 & 2.6 \\
\hline 6 & Infant Mortality Rate (SRS 2008) & 46 & 53 \\
\hline 7 & Maternal Mortality Ratio (SRS 2004 - 2006) & 312 & 254 \\
\hline 8 & Sex Ratio (Census 2001) & 941 & 933 \\
\hline 9 & Population Below the Poverty Line - PBL (\%) & - & 26.10 \\
\hline 10 & Scheduled Caste population (in millions) & 3.19 & 166.64 \\
\hline 11 & Scheduled Tribe population (in millions) & 7.09 & 84.33 \\
\hline 12 & Female Literacy Rate (Census 2001) (\%) & 38.9 & 53.7 \\
\hline
\end{tabular}

Table I: The demographic, socio-economic and health profile of Jharkhand State as compared to all India figures.

* Not applicable as Jharkhand came to being in the year 2000 


\begin{tabular}{|c|c|c|c|}
\hline Particulars & Required & In position & shortfall \\
\hline Sub-centers & 5057 & 3958 & 1099 \\
\hline Primary Health Centers & 806 & 330 & 476 \\
\hline Community Health Centers & 201 & 194 & 7 \\
\hline $\begin{array}{l}\text { Multipurpose worker (Female)/ANM at Sub Centers \& } \\
\text { PHCs }\end{array}$ & 4288 & 5011 & - \\
\hline Health Worker (Male) MPW(M) at Sub Centers & 3958 & 1922 & 2036 \\
\hline Health Assistant (Female)/LHV at PHCs & 330 & - & - \\
\hline Health Assistant (Male) at PHCs & 330 & 660 & - \\
\hline Doctor at PHCs & 330 & 330 & 0 \\
\hline Obstetricians \& Gynecologists at CHCs & 194 & 30 & 164 \\
\hline Physicians at CHCs & 194 & 0 & 194 \\
\hline Pediatricians at $\mathrm{CHCs}$ & 194 & 0 & 194 \\
\hline Total specialists at $\mathrm{CHCs}$ & 776 & 40 & 736 \\
\hline Radiographers & 194 & 0 & 194 \\
\hline Pharmacists & 524 & 348 & 176 \\
\hline Laboratory Technicians & 524 & 381 & 143 \\
\hline Nurses/Midwives & 1688 & 429 & 1259 \\
\hline
\end{tabular}

Table II: Health infrastructure data of Jharkhand

Source: RHS Bulletin, March 2008, M/O Health \& F.W., GOI

The above tabulation of data evidences that health related facilities for the rural poor is indeed struggling to meet community health needs with a significant shortfall. The potential role of SHGs in providing health care services to the poor therefore assumes a significant role in bridging this gap.

\section{Rural women}

In the Indian context, the pattern of society is predominantly patriarchal and Jharkhand is no exception to this trend. Women, especially those of rural areas, have been at the receiving end of caste and class divisions coupled with other inherent problems associated exclusively to women. Consequently, women continue to play a sub-ordinate role both within and outside the family setting, their voice unheard and their potential untapped.

According to the 2001 census figures, the female literacy level in the State stood at a dismal $39 \%$ with the second highest rate of gender disparity in the country save for Rajasthan. The cases of child marriage; miscarriages; anemia; pregnancy deaths; HIV/AIDS and other health related issues are rampant among the female population of rural areas. The sex ratio of Jharkhand is 941 females per 1000 males; the literacy rate 54.13, of which $67.94 \%$ is for males and $39.38 \%$ for females. 
According to the II National Family Health Survey (NFHS) ${ }^{3}$, the State ranks eighth in infant mortality and $14^{\text {th }}$ in child mortality, nationally. High infant and child (under 5) mortality is strongly associated with the high fertility of women and specifically frequent pregnancies. There are substantial territorial variations in infant and child mortality moreover; children born to women of rural low income - specifically illiterate adolescent mothers are at greater disadvantage than those of the privileged classes. Neonatal death is also directly related to the mother's health, which continues to account for two thirds of infant mortality.

The II NFHS provides estimates of infant and child mortality as well as concordant factors associated with the survival of young children. There is some indication, however, that the survey mortality rates are likely to be underestimated. During the five years preceding the survey, the infant mortality rate was 54 (deaths of infants per 1,000 live births), much lower than the infant mortality rate of 78 in Bihar. The child mortality rate in Jharkhand was 25 (deaths of children age 14 years per 1,000 children reaching age one). In all, among 1,000 children born, 78 die before reaching age five. Expressed differently, 1 in 19 children die in the first year of life, and 1 in 13 die before reaching age five ${ }^{4}$.

\section{Occupational structure and work participation}

Women are still at the lower end of the labor market in terms of pay and authority. They typically occupy lower-paid and lower status jobs. The unemployment rate for women is higher than that of men, and women often work informally. In the organized sector, the number of women is significantly small, even if they have the benefit of education and skills. Various socio-cultural factors are responsible for this in a traditionally patriarchal society which discourages women's working outside the house.

There is thus the widespread perception that women have a domestically managerial role to play. Consequently, there is low female participation in formal employment and social prestige is allotted to those females who remain at the centre of both the family unit and the household, without seeking recourse to alternatives. Poverty-stricken families do on occasion allow their women to work should financial means be sparse: she, will, however, work at a disadvantage for education and skills sooner decide the level at which one can enter the labor market and most women find themselves engaged in low-skilled, low-waged work, at times as landless workers, as petty share-croppers in the agriculture sector or contractual wage-laborers in mining and construction. They, together, form an exploited segment of the Indian population and contribute to the number living BPL.

Given this complex scenario, the role of SHGs as a health care option and tool for overall empowerment can prove, for the rural BPL woman, a critically significant possibility.

\section{The workings of SHGs}

In reviewing the working of SHGs in a developing country such as India we are soon to notice that they follow a highly instrumentalized approach with a major emphasis upon savings $\&$ credit facility provisions for the intended client group. This, however, can be overtly economically centered with the concept of empowerment being

\footnotetext{
3 See,http://www.nfhsindia.org/pub nfhs-2.shtml

${ }^{4}$ Child survival programs would do well to focus on specific groups of children with particularly high infant and child mortality rates. Along with various socioeconomic groups, efforts to promote child survival need to concentrate on very young mothers and on those whose children are closely spaced.
} 
reduced to financial terms and the critical issue of health, as well as identity, remaining an important yet unaddressed dimension to social life and human wellbeing.

Appreciating the fact that health plays a crucial role in what qualifies wellbeing and indeed constitutes the identity of human being, it has been reiterated time and again by researchers, policy makers, and in various policy documents that no society or nation can achieve total wellbeing of its people if health is overlooked (Ahuja, $\mathrm{R}$ 2005). In other words, women's empowerment cannot be achieved or indeed seek to fulfill its essential ethos by ignoring or denying issues related to the health of women. Although women's empowerment has been a central issue on the agenda of various developmental programs for so many years, it has surprisingly received little attention and at best it has been pigeonholed into rudimentary activities such as family planning and contraception. The issue of health needs to be tackled in a more comprehensive way, being acknowledged as a contributive factor to identity and citizenship, where the good health of a woman is organically linked with her empowerment both within the household and society.

\section{The district of Deoghar, Jharkhand: some statistical considerations}

Our study is based upon field surveys, interviews and select case studies on a sample of 100 women self help group members in the Deoghar district of Jharkhand State.

Deoghar district was formed in 1983. It had earlier been a sub-division of Santhal Pargana district. It is located in north-eastern Jharkhand and is surrounded by Dumka [North-East], Rajmahal and Bhagalpur; [NorthWest Munger]; Hazaribag [in the West] and Giridih districts [in the South]. The district headquarters is located in Deoghar Town.

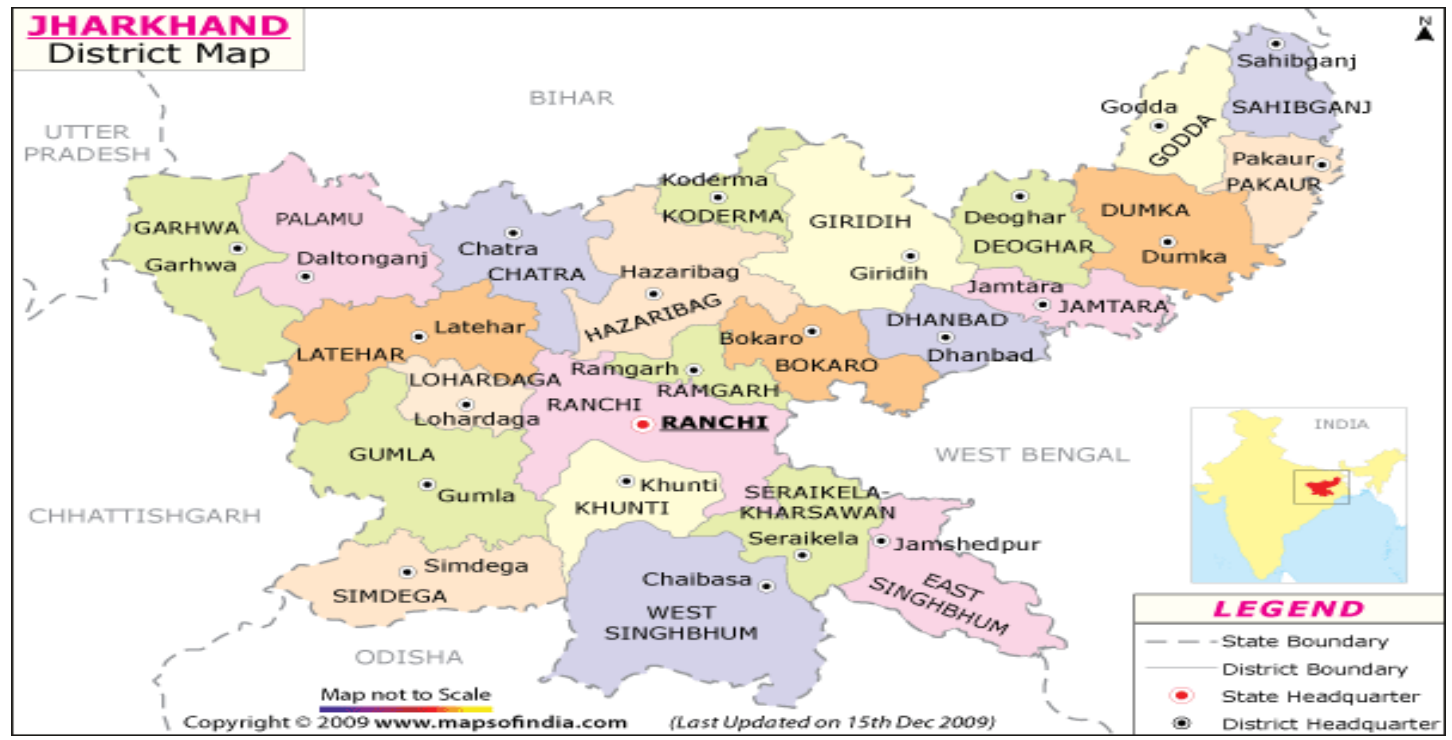

Equity, justic and human rights are complex realities in such geographical areas which mesh with the complicated reality of health access. This, points to the neccessity for livelihood enhancement initiatives and community streghtening strategies, to which either a developing or fully formed SHG can contribute and prove an 
essential mechanism of social development and enhancement.

\begin{tabular}{|c|c|c|}
\hline Indicators & Deoghar District & Jharkhand State \\
\hline Population (in lakhs) & 11.65 & 265.4 \\
\hline Average annual exponential growth rate & 2.44 & 2.31 \\
\hline Population Density (per sq.kms.) & 468 & 338 \\
\hline Sex ratio & 914 & 941 \\
\hline Population & 220003 & 4556827 \\
\hline Male & 111492 & 2522036 \\
\hline Female & 108511 & 2434751 \\
\hline Percentage of literate population & 50.6 & 43.71 \\
\hline Male & 66.9 & 50.07 \\
\hline Female & 32.3 & 31.62 \\
\hline Urban Percentage & 13.8 & 22.24 \\
\hline
\end{tabular}

Table 3: research findings of demographic indicators for Deoghar

The population density and annual exponential growth rate of the district, as evidenced by our tabulated research (Table 3) is higher as compared to Jharkhand State. The district also has a lower sex ratio, and reported to have a literacy rate of 50.6 percent ( $66.9 \%$ males \& $32.3 \%$ females). Approximately 12.8 percent of the population of the district lives in urban areas in contrast to 22.24 percent in the State. 


\section{Women's empowerment and welfare agencies}

Among the several agencies functioning in the Deoghar district towards the welfare of the marginalized sections of the society, NEEDS (Network for Enterprise Enhancement \& Development Support), has been extremely active. In context of the present study we sought to assess the workings of this NGO and the precise move towards the socio-economic upliftment $\&$ health related facilities provided to the underprivileged sections in the district with special emphasis upon women.

NEEDS works actively with issues of safe motherhood and child survival, the goal is to catalyze sustainable improvement of maternal and newborn health status through effective community action.

The main objectives of the safe motherhood program are to:

- Significantly increase individual, household and community action that directly and indirectly improve maternal and newborn health.

- Enhance systems and institutional capabilities for sustained improvement in maternal and newborn health care services and health status.

NEEDS is directly implementing the program on adolescent reproductive and sexual health [ARSH] in two blocks of Deoghar district. In 2007 there were 60 teen centers and youth clubs for the 13-23 age group. The centers seek to improve life skills and helping community continuity by enhancing the service delivery of reproductive health services. Optimum community participation is encouraged by involving religious leaders and other opinion makers who have ensured community trust. In this process NEEDS facilitated a grassroots organization network to scale up the ARSH program in Santhalpargana region. This group is known as DISHA [Development Intervention in the Sexual Health of Adolescents]. The DISHA network is operational in the districts of Deoghar, Pakur, Jamtara and Giridih.

\section{Research}

\section{Research sample and methodology}

Our study was undertaken with the specific objective of estimating the level of health care services provided by the SHGs and the awareness and satisfaction level of their members.

No previous studies had been conducted in Deoghar district, assessing the health care services provided by SHGs. In Deoghar the SHGs, which are in the initial, fledgling stages of development, function with the help of a President and Secretary. Members were randomly selected from 10 SHGs with one leader and one animator from each group. Both qualitative and quantitative methods were employed to critically explore the existing linkages between SHGs, women empowerment and its impact upon female health. Women self help group members were interviewed and selected case studies were conducted. The interviews aimed at obtaining an idea of the problems envisaged and the prospects of involving SHG in health related work. Select focus group discussions (FGDs) were conducted with group members from selected SHGs. FGDs were aimed at determining individual members' perceptions about roles, expectations and health achievements

Most of the respondents (73) were in the age group of 30-40 years, 17 respondents were in the age group of 20-30 years and only 10 respondents were above 40 years of age. Most respondents (79) studied up to $10^{\text {th }}$ standard grade, 19 respondents were illiterate and 2 respondents studied higher secondary education courses. $97 \%$ of the respondents were married, $2 \%$ unmarried and $1 \%$ were widowed. Only $13 \%$ of the respondents reside in their own 
houses while $87 \%$ reside in rental accommodation.

Five variables covering the impact of SHGs on health related services of rural women were identified. The measurement was graded through the Likert scale and scores were assigned for each statement. A high score of 5 was given to strongly agreed responses with a low score of 1 for statements of strong disagreement. Analysis of the impact of SHGs on health related issues is presented by way of tabulation:

\begin{tabular}{|c|c|c|}
\hline \multirow[t]{2}{*}{ SHG impact on: } & \multicolumn{2}{|c|}{ Total } \\
\hline & *Count & $* \mathrm{Col} \%$ \\
\hline $\begin{array}{l}\text { Awareness of health \& } \\
\text { sanitation }\end{array}$ & & \\
\hline Increase & 67 & 67 \\
\hline Decrease & 18 & 18 \\
\hline No Change & 15 & 15 \\
\hline \multicolumn{3}{|l|}{ Awareness of food \& nutrition } \\
\hline Increase & 56 & 56 \\
\hline Decrease & 03 & 03 \\
\hline No Change & 41 & 41 \\
\hline \multicolumn{3}{|l|}{ Care during pregnancy } \\
\hline Increase & 50 & 50 \\
\hline Decrease & 04 & 04 \\
\hline No Change & 46 & 46 \\
\hline \multicolumn{3}{|l|}{ Awareness of personal health care needs } \\
\hline Increase & 63 & 63 \\
\hline
\end{tabular}




\begin{tabular}{|c|c|c|}
\hline Decrease & 02 & 02 \\
\hline No Change & 35 & 35 \\
\hline Awareness about existing health services & & \\
\hline Increase & 69 & 69 \\
\hline Decrease & 01 & 01 \\
\hline No Change & 30 & 30 \\
\hline
\end{tabular}

Table IV: Impact of SHGs on health awareness, knowledge \& services offered

* Count refers to the number of respondents and column\% indicates their percentage out of the sample size of 100. They are the same due to the sample size being 100 for the purpose of this study.

\section{Discussion of preliminary findings}

Such preliminary findings help to understand the process inputs affecting women's empowerment and the social health status of women in the district. Most of the women interviewed were Hindus who are the predominant inhabitants. The women, all of equal economic status, were however of different genealogical castes such as the Paswan, Yadav, and Kurmi. In terms of lifestyle, the respondents presented a great deal of homogeneity.

Our initial research found that the majority of women collectively perceived a positive change in their health status after joining the group:

Earlier who used to care for us? If I said I want a small family and better health for my kids I was not paid attention by my husband as I was alone and not an earning member of the family. After joining the group things have definitely changed for the better. We are better informed now and we take our kids to the health centre regularly." (Respondent 10)

I am so happy that I succeeded in convincing my husband to use contraceptives and now we are happily engaged in looking after our three kids well. We are not planning to extend our family any further. I think the self help group has helped me and my views are now taken seriously by my family especially in issues related to our health (Respondent 5)

Such testimony evidences not merely the re-evaluation of roles and identity's within the household, but an allotting of value and actualization of self-value through engagement with the SHG.

The women also attended the govt. sponsored polio eradication programs where their children received polio drops, despite the fully fledged vaccination being unavailable in health centers. The children are yet to be fully vaccinated. However, our research findings also indicate that economic benefits may not have necessarily influenced health behavior. Only $40 \%$ of SHG members felt that finance brought improvements to health, this indicating both psycho-social factors and access to programs. Findings also do not indicate that the SHG has been successful in enhancing health related knowledge level significantly, more time, and a greater sample is required. This said the 
utilization of private health services has increased via the supporting SHG:

I went to the health care centre yesterday and the doctor gave some medicines for my kid. He has called me to come after 15 days again. My neighbors are also joining me in my visits but we are not sure about what medicines are being given and for what purpose. But we will regularly visit the centre. They are not charging any money from us." (Respondent 7)

As far as improving women's health status through SHGs is concerned, it has been observed by our small study that most SHGs whose basic focus is upon economic issues (savings \& credit facilities for the members) have not performed satisfactorily in enhancing the knowledge and awareness on health related issues among women. In recent times women have gained appreciably as a result of joining SHGs and thereby being able to meet their health related expenditure by borrowing money from the group:

We are no longer dependent on any one for borrowing money in times of medical emergencies. We do not feel helpless. We can withdraw money from the group. Earlier we used to take money from the money lender. The interest rate used to be high: three to four rupees per hundred. Here the interest rate is cheaper, two rupees per hundred. We can return this money in monthly installments. The money we took from the moneylender had to be returned in one go. Recently I borrowed Rupees ten thousand to get an operation done as advised my doctor in town. I will repay the money in easy installments. (Respondent 9)

SHGs can play a role in creating awareness of health issues through necessary group meetings with women, by holding specific capacity-building trainings on health issues and facilitating exposure to important up-to-date medical information. The members need to be au fait with medical issues and health promotion, this, equally indicating the responsibility of the SHG to fulfill its role for both women and the community. This said, a substantial influence on women's health and empowerment can only be achieved when these activities are taken up with a view to improving the public provision of health care facilities and accessibility, particularly in light of the RSBY initiative.

It can be said that SHGs have indeed emerged as a health care option for women and their families who join these groups but still further awareness, and much greater detailed research is required among the existing SHGs in these geographical areas to ensure the move away from the uni-dimensional market oriented view of employment generation and social actualization.

We urge greater in depth research to be undertaken into SHGs and a structural paradigm of enquiry set up to chart the evolution and social articulation of SHG members. More evidence is needed to ascertain the consistency and long-term accomplishments of SHGs, not just to ensure the economic empowerment of women, but their health status and wellbeing

\section{Bibliography}

Ahuja, R. (2005). Universal Health Insurance Scheme. Yojana. Vol. 49, July 2005. New Delhi. Ministry of Information and Broadcasting:

Fernandez Aloysius P., The MYRADA Experience - People's Institutions for sustained and equitable management of micro-watersheds, 2/e Bangalore: MYRADA, 1994

Health Care and Women's Empowerment

Volume 2, No. 1 (2012) | ISSN 2161-6590 (online) | DOI 10.5195/hcs.2012.56 | http://hcs.pitt.edu 
H.S. Shylendra (1998), Promoting Women's Self Help Groups: Lessons from an Action Research Project, Working Paper No. 121, Institute of Rural Management, Anand.

Jayapalan (2001). Indian society and social institutions, Atlantic Publishers \& Distributors.

Katz AH (1981), Self help and mutual aid: An emerging social movement? Annual

Review of sociology, 7:129-155: What future role in health care for low and middle-income countries? International Journal for Equity in Health 2004,3:1

Kumar Anant (2006). Self Help Groups, Women's Health and Empowerment: Global Thinking and Contextual Issues, Jharkhand Journal of Development and Management Studies XISS, Ranchi, Vol. 4. No.3, September 2006, pp 2061-2079

Narayan, Deepa (2002), Empowerment and Poverty Reduction: A Source book.Washington: World Bank

R. C. Majumdar and A. D. Pusalker (editors): The history and culture of the Indian people. Volume I, The Vedic age. Bombay: Bharatiya Vidya Bhavan 1951,p.394

Rowland, J. (1998). A Word of the Times, but What Does it Mean? Empowerment in the Discourse and practice of Development in Afshar, Haleh. 1998.

Robinson D(1980), The Self Help Component of Primary Health Care, Social Science and Medicine, 14 A: 415-421

Robinson D(1981), Self Help Groups in Primary Health Care, World Health Forum, 2: 185-191

Stiglitz, J. (1993), Peer Monitoring and Credit Markets, World Bank Economic Review, Vol. 4, No. 3 (1993): pp. 351-366. 